\title{
A multi-level approach to addressing mental health stigma in Canada
}

\section{Thilina Bandara}

\section{University of Saskatchewan}

For the approximately 6.7 million Canadians who experience mental health issues, isolation, social exclusion, and discrimination associated with stigma continue to prevent many from seeking help..$^{1,2}$ In 2012, Canada became the last G8 country to draft an official national mental health strategy to improve the lives of those affected by mental illness. According to the Mental Health Commission of Canada's (MHCC) Changing directions, changing lives: The mental health strategy for Canada, everyone has a role to play in eliminating stigma against those living with mental health issues. ${ }^{3}$ While many anti-stigma campaigns have been piloted across Canada, this new strategy formalizes leadership and promotes the implementation of a national program. With this important step, the opportunity for large-scale advancements in mental health has arrived, including the potential to collectively address stigma.

Stigma and negative stereotypes against those with mental health issues can manifest as discrimination, including denial of employment, limited housing options, and marginalization from professionals towards those with a history of mental health concerns. ${ }^{4,5}$ The highly complex nature of this problem requires leadership and coordination. In Canada, former Senator Michael Kirby has demonstrated such leadership through his long-term commitment to reducing stigma against people with mental health diagnoses. By introducing this topic to the senate in 2006, and with his subsequent advocacy work, his goal is to create a national movement against stigma. ${ }^{6}$

Anti-stigma initiatives must be evidence-based and include successful advocacy, targeted interventions, and participatory approaches to research. At the macro level, advocacy can help mitigate stigma-perpetuating behaviors in the media. An example of influential anti-stigma advocacy was the cancellation of the American Broadcasting Corporation's (ABC) television drama, Wonderland in 2000. $A B C$ 's decision to stop the show has been attributed to heavy backlash from mental health organizations regarding the show's characterization of mental health patients as dangerous and violent. Though unlikely to eradicate individual stigmatizing attitudes, organizational advocacy such as this has the potential to build awareness of stigma across large audiences. ${ }^{7,8}$ The recent 'Let's Talk' campaign launched by Bell Canada Telecommunications Corporation was an encouraging step towards further awareness and dialogue at the national level. Designed as a fundraising event, Bell Canada donated 5 cents for each long distance call, text, 'Let's talk' tweet, and Facebook share that occurred on February 14, 2013. Thanks to over 96 million communications, Bell Canada raised over 4.8 million dollars for Canadian mental health programs. ${ }^{9}$ Similar efforts must continue to be evaluated for their effectiveness.

Targeted anti-stigma campaigns demand a multi-pronged approached. As Corrigan et al. ${ }^{7}$ point out in their metaanalysis of anti-stigma campaigns, there is no one method that will change attitudes associated with mental illness. Their results suggest that mental health educational campaigns are especially effective in adolescent groups, while person-to-person contact with those who have experienced mental health issues has been shown to be beneficial with adults., ${ }^{7,10}$ For example, an evaluation of a pilot anti-stigma program that incorporated personal stories from self-advocates who had experienced mental illness demonstrated positive attitude change among health care workers in British Columbia. ${ }^{11}$.

Integrating mental health consumers into research is another potential avenue for reducing stigma. The Canadian Mental Health Strategy ${ }^{3}$ emphasizes the value of including those affected by mental health issues into the all levels of action, to discuss explicitly what worked for them, what areas are deficient, and where resources are best allocated. For example, the research agenda put forward in the Strategy provides a highly compelling 
case for inclusive study designs by encouraging the use of both the traditional biomedical approaches - psychosocial, clinical, and neuroscience research, as well methods that incorporate those impacted by mental illness into the creation of knowledge and practices based on lived experience. ${ }^{3}$ Framing the national discussion on mental health with people who have experienced or are currently experiencing mental health concerns is another important step towards reducing stigma.

With a renewed sense of direction, Canadians have an opportunity to progress the mental health agenda and alleviate the effects of stigma so that individuals can confidently access recovery services. Taking part in social activism, conducting evidence-based targeted campaigns, and practicing inclusivity in research methods can increase awareness of stigma among those in the field. While the authors of Canada's Mental Health Strategy are quick to admit that their large-scale recommendations to address systemic deficiencies in mental health care will take years to properly implement, helping to reduce stigma is one way we can improve the well-being of all Canadians today.

\section{References}

1. Mental Health Commission of Canada. Why investing in mental health will contribute to Canada's economic prosperity and to the sustainability of our health care system [document on the Internet]. c2012 [cited 2012 Feb 7]. Available from: http://strategy.mentalhealthcommission.ca/pdf/case-forinvestment-en.pdf

2. Corbiere M, Samson E, Villotti P, Pelletier J-F. Strategies to fight stigma toward people with mental disorders: Perspectives from different stakeholders. The Scientific World Journal [serial online]. 2012 [cited 2013 Feb 5]; DOI: 10.1100/2012/516358.

3. Mental Health Commission of Canada. Changing directions, changing lives: The mental health strategy for Canada. [document on the Internet]. Calgary, AB: 2012 [cited 2013 Feb 7]. Available from: http://strategy. mentalhealthcommission.ca/pdf/strategy-images-en.pdf

4. Corrigan PW. Mental health stigma as social attribution: Implications for research methods and attitude change. Clin Psychol-Sci Pr. 2000;7(1):48-67.

5. Sartorius N. Short-lived campaigns are not enough. Nature. 2010;468:163-165.

6. Goar C. Michael Kirby cuts his government safety net to lead private drive for mental health. The Star: Toronto Star Newspaper [serial online]. 2012 [cited 2013 Mar 25]. Available from: http://tinyurl.com/c4pmvdc

7. Corrigan PW, Morris SB, Michaels PJ, Rafacz JD, Rusch N. Challenging the public stigma of mental illness: A meta-analysis of outcome studies. Psych Serv. 2012;63(10): 953-973.

8. National Alliance on Mental Illness. Wonderland premier brings call on White House to fight stigma in entertainment industry [homepage on the Internet]. c2010 [updated 2000 Mar 30; cited 2013 Mar 23] Available from: http://tinyurl.com/lc5353

9. CTV news team. More than $\$ 4.8 \mathrm{M}$ raised for mental health during Bell Let's Talk Day. [serial online]. 2013 [cited 2013 Apr 15]. Available from: http://www.ctvnews.ca/health/more-than-4-8m-raised-for-mental-healthduring-bell-let-s-talk-day-1.1154801

10. Evans-Lacko S, London J, Japhet S, Rusch N, Flach C, Corker E, Henderson C, Thornicroft, G. Mass social contact interventions and their effect on mental health related stigma and intended discrimination. BMC Public Health. 2012;12(489):1-8.

11. Modgill G, Patten S. British Columbia's Interior Health Authority's usage of the Ontario Central LHIN Anti-Stigma Training Program: An independent evaluation by Opening Minds. No date [cited 2013 March 23] Available from: http://www.mentalhealthcommission.ca/English/system/files/private/ document/stigma_opening_minds_bc_interior_health_authoritys_ eng_0_0.pdf

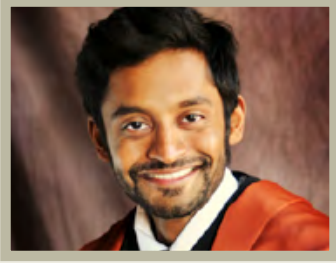

\section{Thilina Bandara}

Thilina Bandara received both a BSc in Physiology and Master of Public Health from the University of Saskatchewan. He currently a part of the Healthy Children Team at the Saskatchewan Population Health and Evaluation Research Unit (SPHERU). His research interests include knowledge translation, health equity and evidence-based interventions and practice. 